\title{
POLÍTICA Y RELIGIÓN: ¿PUEDE EL SÍMBOLO RELIGIOSO DEJAR DE SERLO POR SU USO APOLOGÉTICO-FRANQUISTA?
}

\section{POLITICS AND RELIGION: CAN THE RELIGIOUS SYMBOL CEASE TO BE SO BECAUSE OF ITS APOLOGETIC-FRANCOIST USE?}

\author{
Manuel Alenda Salinas \\ Matilde Pineda Marcos \\ Universidad de Alicante. Alicante/España \\ manuel.alenda@ua.es \\ matilde.pineda@ua.es
}

Recibido/Received: 17/07/2018

Modificado/Modified: 01/09/2018

Aceptado/Accepted: 22/09/2018

\section{RESUMEN}

El presente artículo, tras el análisis de la doctrina científica y jurisprudencial existente en la materia, explora el significado que ha de atribuirse a las "cruces de caídos", a los efectos de la aplicación del artículo 15 de la conocida como Ley de Memoria Histórica. Los resultados obtenidos constituyen base jurídica suficiente como para poder concluir la inaplicabilidad de este precepto en el asunto estudiado.

\section{PALABRAS CLAVE}

Simbología religiosa; laicismo; dictadura franquista; memoria histórica; "cruces de caídos".

\section{SUMARIO}

1. Introducción. 2. Los casos judicializados: 2.1. Las cruces de Mota del Cuervo (Cuenca). 2.2. La cruz de los caídos de Vigo (Pontevedra). 2.3. El monumento a los caídos de Buñuel (Navarra). 2. 4. La cruz de los caídos de Callosa de Segura (Alicante). 3.- ¿La cruz de caídos es evocadora de religiosidad o del fascismo? 3.1. Significado originario. 3.2. Significado en el tardofranquismo, la transición y primeros tiempos democráticos. 3.3. Significado actual. 4. ¿La cruz de caídos entra en el ámbito de aplicación del art. 15.1 de la Ley de Memoria Histórica? 5. Conclusiones. Bibliografía.

\footnotetext{
ABSTRACT

The present paper, after analyzing the existing and related scientific and new case law doctrine, explores the meaning to be attributed to the "fallen crosses", for the purposes of the application of article 15 of the so-called Historical Memory Act. The results constitute a sufficient legal basis to be able to conclude the inapplicability of this law provision in this case.
}

\section{KEYWORDS}

Religious Symbology; Secularism; Franco Dictatorship; Historical Memory; "Fallen Crosses". 


\section{CONTENTS}

1. Introduction. 2. The cases filed before the Courts: 2.1. The crosses of Mota del Cuervo (Cuenca). 2.2. The fallen cross of Vigo (Pontevedra). 2.3. The monument to the fallen of Buñuel (Navarra). 2. 4. The fallen cross of Callosa de Segura (Alicante). 3. Is the fallen cross evocative of religiousness or fascism? 3.1. Original meaning. 3.2. Meaning in the late Francoism, the transition and early democratic times. 3.3. Current meaning. 4. Does the fallen cross fall within the scope of art. 15.1 of the Historical Memory Act? 5. Conclusions. References.

\section{INTRODUCCIÓN}

De un tiempo a esta parte el panorama español se ha visto salpicado de diferentes conflictos ocasionados por la interpretación y aplicación del art. 15 de la Ley 52/2007, de 26 de diciembre, por la que se reconocen y amplían derechos y se establecen medidas en favor de quienes padecieron persecución o violencia durante la guerra civil y la dictadura, más conocida como Ley de Memoria Histórica, en adelante LMH, algunos de los cuales han desembocado en los Tribunales. El precepto acabado de citar señala, en sus dos primeros apartados: "1.- Las Administraciones públicas, en el ejercicio de sus competencias, tomarán las medidas oportunas para la retirada de escudos, insignias, placas y otros objetos o menciones conmemorativas de exaltación, personal o colectiva, de la sublevación militar, de la Guerra Civil y de la represión de la Dictadura. Entre estas medidas podrá incluirse la retirada de subvenciones o ayudas públicas. 2.- Lo previsto en el apartado anterior no será de aplicación cuando las menciones sean de estricto recuerdo privado, sin exaltación de los enfrentados, o cuando concurran razones artísticas, arquitectónicas o artístico-religiosas protegidas por la ley".

Variados son los supuestos en que se ha manifestado esta litigiosidad, como los relativos al cambio de nombres de calles cuya patronímica se liga al franquismo, la Guerra civil y/o a la Dictadura y, en algunas ocasiones, hasta el cambio de la denominación de pueblos por su ligazón, también, con el franquismo, retiradas de estatuas del General Franco, etc. Pero nos interesa, en particular, la temática relativa a los conocidos como "Monumentos a los caídos" y, más en concreto, cuando se trata de "Cruces de caídos".

El tema no es nuevo, y se ha ido suscitando desde los más cercanos tiempos a la muerte del dictador. Alguno de estos supuestos se solucionó por la vía política: caso, por ejemplo, de Alicante, cuyo Alcalde, Sr. Lassaletta, en 1987, transformó la originaria dedicatoria contenida en el Monumento a los caídos [del bando vencedor] por la de "1936-1940. A todos los hombres y mujeres que murieron en defensa de sus ideales" (Campello, 2009). Aunque más recientemente, y al amparo de la citada $\mathrm{LMH}$, se postula la retirada de la misma (un resumen de la polémica en $\mathrm{CP}, 2017)$. Otros casos, sin embargo, culminaron en los Tribunales: Así, la retirada de la Cruz de caídos dispuesta por el Ayuntamiento de Burriana, en Acuerdo de 7/1/1988, se declaró no ajustada a Derecho por el Tribunal Supremo en Sentencia de 8/5/1996, al considerar que, formando parte de un bien de dominio público, no había sido objeto de la requerida previa desafectación. La Sentencia puede consultarse en Iustel.com, RI §314615.

Pero ha sido sobre todo al albur de la LMH -y otras que, en el ámbito de algunas Comunidades Autónomas, especialmente la andaluza, balear y valenciana, la han secundadoque, más recientemente, los medios de comunicación nos dan noticia de las enfrentadas opiniones que, al modo de las otrora "dos Españas", se manifiestan al respecto, propugnando, unos, la retirada de dichas Cruces de caídos al ser tildadas de franquistas y, como tales, 
consideradas contrarias a dicha LMH y, por otro lado, quienes estiman que tales Cruces, al menos despojadas de sus "elementos franquistas", no constituyen más que símbolos religiosos. En efecto, últimamente han salido a la luz, como representativos de esta conflictividad, entre otros, supuestos como el del Monumento a los caídos de Villarrobledo, en Albacete, así como el de Pamplona (para situarse en la polémica, puede consultarse: Muñoz, 2018), la Cruz del parque de Ribalta en Castellón ("una plataforma denunciará a la alcaldesa de Castellón si retira la cruz del parque Ribalta", según Europa Press, 2018). Otros casos han terminado en sede judicial. Entre éstos ha adquirido bastante dosis de celebridad el relativo a la Cruz de caídos de Callosa de Segura (Alicante), que ha dado lugar a varios procesos judiciales, algunos todavía vivos, pero en los dos casos en que al respecto ya ha recaído sentencia, y ha alcanzado firmeza, ésta se ha apartado de los precedentes judiciales en la materia. Pasaremos a examinar estos supuestos con mayor detenimiento y, al hilo de los mismos, nos adentraremos en algunos de los interrogantes que suscitan (para un examen con carácter monográfico: Abad, 2009).

\section{LOS CASOS JUDICIALIZADOS}

\subsection{Las cruces de Mota del Cuervo (Cuenca)}

Hasta en tres ocasiones hubo de pronunciarse el Juzgado Cont.-Admvo. $\mathrm{N}^{\mathrm{o}} 1$ de Cuenca respecto al ajuste a Derecho del Acuerdo municipal de retirar una cruz de la plaza del pueblo, adyacente a la iglesia parroquial, y otras dos cruces sitas en el cementerio municipal; siendo resueltos, los tres casos, en el sentido de acordar la restitución de los símbolos religiosos a su primigenia ubicación, si bien una vez despojadas las cruces de los elementos que podían suponer una contrariedad con la LMH (entre la poca bibliografía, específica, sobre la materia, sí se ha ocupado de la misma De Lemus, 2016: 106 ss.). En efecto, dos Sentencias, Nº 66 y 67, ambas de 23/2/2010 -Roj: SJCA 149/2010, Roj: SJCA 150/2010, respectivamente- y otra, la No 73, de 25/2/2010 -Roj: SJCA 151/2010-, ordenan reponer en su respectivo lugar, las cruces que habían sido retiradas por el Consistorio. La decisión judicial se fundamenta con una argumentación prácticamente idéntica, dada la semejanza de la ratio iuris decidendi en los tres supuestos.

En primer lugar, en las dos Sentencias relativas a las cruces que fueron retiradas del cementerio, se sale al paso de la objeción suscitada por la parte demandada, relativa a la falta de legitimación activa de la parte demandante (constituida por familiares de personas cuyos nombres aparecían en las cruces). Se alegaba, al respecto, la falta de legitimación dado que no se trataba ni de una sepultura ni de un monumento privado, que incluso se llegaba a desconocer la exacta ubicación de los restos de los difuntos en cuestión y, que, en cualquier caso, el monumento podía ser retirado sin daños a la base que lo sustentaba puesto que era en dicha base donde figuraban los nombres de los familiares fallecidos por los que se litigaba por parte de la actora.

Las resoluciones judiciales aseveran que todos estos datos son intrascendentes a este respecto, por lo que no se puede negar la legitimación activa de los demandantes, siquiera fuera de tipo emocional, puesto que la pretensión de los familiares impugnantes de la actuación administrativa era, precisamente, el que se mantuviera la memoria de los fallecidos, que es la razón de ser del monumento en cuestión. En concreto, se afirma en las Sentencias: "lo esencial en ese caso, desde la perspectiva que nos ocupa, [...] es el mantenimiento incólume de dicha memoria, como un homenaje a las personas que allí se reflejan, algo que es lógico y razonable que los familiares de los mismos quieran preservar y 
desde esta perspectiva, por tanto, está plenamente justificado su interés en el presente pleito, al pretender mantener dicho monumento allí erigido, con las connotaciones emocionales que ello conlleva, y la improcedencia de la alegación de falta de legitimación activa planteada por las partes demandadas" -F.D. $2^{\circ}$ de las Sents. 66 y 67, de 23/2/2010-.

En el tercer caso litigioso, referente a la cruz inmediata al templo parroquial, la Sentencia considera también concurrente la legitimación activa de la demandante (en este caso la diócesis de Cuenca), dado que, frente al alegato de que el monumento retirado es un bien de dominio público del municipio, se afirma que, con independencia de la titularidad del monumento, cuestión que se estima propia de dilucidar en la jurisdicción civil, "lo que late en el presente caso es la retirada de un monumento, en concreto, una Cruz, adosada o cercana a la pared de la Iglesia Parroquial, entre los contrafuertes de la misma, con una verja que la separa del acerado, que forma parte, de manera efectiva, del entorno parroquial que la parte actora pretende preservar, y desde esa perspectiva, por tanto, dada la peculiar situación de la Cruz, tan íntimamente asociada a la Iglesia, como deriva de las fotografias obrantes en las actuaciones, no hay inconveniente para aceptar el interés legítimo de la parte recurrente en preservar dicho entorno de la iglesia parroquial, manteniendo dicha Cruz en su situación original, como así se ha mantenido durante muchos años, vinculada en su aspecto exterior a la Parroquia" -F.D. $2^{\circ}$ de la Sent. 73, de 25/2/2010; las cursivas son nuestras-.

Por lo que respecta al fondo del asunto, el juzgador de los tres casos parte, desde el principio, del desiderátum de que hay que conciliar los intereses de las partes en conflicto, para lo que considera que hay base en el espíritu y finalidad de la propia LMH. Y afirmándose en el carácter religioso del símbolo, así como en la exaltación meramente de recuerdo privado de los fallecidos, que no público ni de exaltación de la Guerra Civil ni de la Dictadura, resuelve que las cruces han de volver a su lugar originario; ahora bien, a efectos de evitar esa exaltación proscrita por la Ley en cuestión, ordena que las tres cruces sean "liberadas" de los lemas, símbolos o inscripciones que sí responden a esa exaltación de la Guerra o de la subsiguiente Dictadura; en concreto aseveran las sentencias: "considerando como tal [...] la simbología que alude al franquismo, que se halla en la parte frontal, que consta de un escudo oficial de la época y una inscripción labrada en la piedra y bajo el escudo que reza «Caídos por Dios y por España. ¡Presentes!», lemas, expresiones y símbolos que sí deben desaparecer para respetar el contenido de la Ley 52/07, no así el monumento de la Cruz como tal, como símbolo meramente religioso, y los nombres de los fallecidos, como una mención de estricto carácter privado sin más" -F.D. $4^{\circ}$, in fine, de las dos Sents. de 23/2/2010 y F.D. $5^{\circ}$, in fine, de la Sent. de 25/2/2010-

Con ser loable el propósito judicial -y hasta poder llegar a coincidirse con él en cuanto al conjunto de la solución final alcanzada-, lo cierto es que en el desarrollo de las Sentencias se viene a construir las mismas, a nuestro juicio, en modo rayano en lo salomónico, y ello hasta el punto de poder llegar a percibirse contradicción entre la fundamentación jurídica que se esgrime. Y llegamos a esta conclusión, puesto que en uno de los FF.D. de las Resoluciones en cuestión se llega a afirmar que lo que ha de prevalecer, en el momento actual, es que se trata de un símbolo religioso con menciones de estricto recuerdo privado hacia las personas muertas cuyos nombres figuran en las cruces; hasta el punto de significar que se está más propiamente en el caso del núm. 2 del art. 15 de la LMH, llegando a aseverar que "conforme a las previsiones de la propia Ley 52/07 que el Ayuntamiento dice aplicar, no está justificada la retirada de su ubicación en los términos referidos" -F.D. $3^{\circ}$ de las dos Sents. de 23/2/2010 y F.D. $4^{\circ}$ de la Sent. de 25/2/2010-. Sin embargo, en el Fundamento siguiente de las Resoluciones judiciales se viene a poner en tela de juicio, cuando no directamente se contradice, lo acabado de sostener, desde el momento en que señala que, para cuanto 
antecede, es preciso despojar a las cruces de "todos los símbolos y expresiones típicas y alusivas al régimen franquista, pues ello sí que supondría la exaltación de dicho régimen" F.D. $4^{\circ}$ de las dos Sents. de 23/2/2010 y F.D. $5^{\circ}$ de la Sent. de 25/2/2010-.

Pero la solución judicial no contentó a todos y, por esta razón, las tres Sentencias fueron en su día oportunamente recurridas para ante el Tribunal Superior de Justicia, en adelante TSJ, de Castilla-La Mancha, por parte del Ayuntamiento; sin embargo, con motivo del cambio de partido en el gobierno municipal, a consecuencia del resultado de unas nuevas elecciones, quedaron firmes al haberse retirado dichos recursos por el Consistorio (De Lemus, 2014: 21).

Sin embargo, lo que está en el fondo del asunto y debería de haberse planteado es que quien contempla la cruz, ¿qué es lo que percibe? ¿Un símbolo religioso o, según es calificado por algunos, un símbolo fascista? Por otro lado, ¿constituye un conjunto indivisible o las insignias son perfectamente separables de la cruz?

\subsection{La Cruz de los Caídos de Vigo (Pontevedra)}

Más recientemente en el tiempo, el TSJ de Galicia ha dictado la Sent. N ${ }^{0}$ 54, de 5/2/2015, Roj: STSJ GAL 536/2015, revocando la Sent. del Juzgado Cont.-Admvo. No 2 de Vigo, de 4/9/2014, que había condenado al Concello de Vigo a que procediera de forma inmediata a adoptar las medidas oportunas para la retirada de la "Cruz de los caídos" ubicada en el Monte do Castro de Vigo. Para llegar a esta conclusión revocatoria, la Sentencia del alto Tribunal gallego pone de relieve que es necesario estar al momento actual, y no al primigenio, para desentrañar el significado del símbolo, que hoy -dice la resolución judicialha de tenerse por religioso, dado que, además, el sentido franquista de que pudo adolecer fue debidamente eliminado, al suprimirse los elementos que pudieran ser representativos de la Guerra civil o de la Dictadura.

Señala, en concreto, la Sentencia, en su F.J. 3, que "aun admitiendo que originariamente tuviera un significado de exaltación de la guerra civil y de la dictadura, no puede compartirse que hoy, una vez desaparecida toda la simbología fascista a que más arriba se hizo referencia [...] siga teniendo ese componente de exaltación inicial, habiendo desaparecido su carga política, y puede ser contemplada como un elemento religioso, aunque no fuera su significado originario, puesto que es evidente que se trata de una cruz latina". Hay que poner de relieve que antes de la contienda judicial se había procedido a la retirada del "sarcófago, las dos coronas de laurel en bronce, la inscripción «Caídos por Dios y por España ¡Presentes 1936-1939», los escudos preconstitucionales, los emblemas de la falange y los requetés", según el F.J. $2^{\circ}$ de la Sentencia.

Yendo, incluso, un paso más allá, y en lo que algún autor ha querido ver un argumento de suma trascendencia, no sólo a los efectos de la adecuada interpretación del fondo de la cuestión litigiosa, sino de la propia Ley 52/2007 (Fernández de Gatta, 2015: 301), se asevera en la Sentencia que tal símbolo en la actualidad sirve también a los efectos de la "Memoria Histórica", pues -en palabras de la propia resolución judicial- "no se puede obviar que la cruz también refleja la persecución por razones políticas en un contexto histórico que no ha de ser olvidado para que no se repita, de forma que ha de conservarse esa memoria, pero no en el sentido de exaltación de los valores franquistas sino en el de que permita reflexionar sobre el pasado, una vez desaparecido el componente político inicial y dado el contexto político actual. Como ese aspecto de exaltación ha desaparecido, no se da la exigencia del art. 15 [de la LMH]. Y contemplada a día de hoy, al margen de las creencias superadas que motivaron su construcción, como muchos otros monumentos a lo largo de la historia de la humanidad, ha de llevar al conocimiento y reflexión por las generaciones presentes y futuras 
sobre un pasado ya superado pero que no ha de olvidarse, habiendo de considerarse representativo de los caídos de ambos bandos»-F.J. 3; los corchetes, con su contenido y cursivas, son nuestros-.

Dado el sentido convencional y, por tanto, colectivo que ha de darse al símbolo si hemos de atenernos a la jurisprudencia del Tribunal Constitucional -en este sentido son de citar las Sentencias 94/1985, de 29 de julio, 130/1991, de 6 de junio y 34/2011, de 28 de marzo-, no podemos sino coincidir, en este punto, con cuanto en el análisis de esta Sentencia se sostuvo, en su día: "ya que es necesario estar al significado actual del símbolo, por mucho que el mismo pretendiera ser variado en otros tiempos mediante aditamentos que ya no subsistan, de modo que el significado político de antaño no debe de prevalecer sobre el sentimiento social de un tiempo más presente" (Alenda, 2016: 355).

\subsection{El Monumento a los Caídos de Buñuel (Navarra)}

Todavía con anterioridad en el tiempo, en la que parece ser la primera resolución judicial que alcanzó el mismo techo jurisdiccional que la precedente, la Sentencia del TSJ de Navarra, de 19/9/2014, confirmando la pronunciada en la primera instancia, se decantó por una intelección de los hechos enjuiciados bajo la mira de la LMH en un sentido muy similar al que luego mantendría el Tribunal gallego en la decisión que acabamos de comentar. En este supuesto concreto se trataba más propiamente de un monolito que de una simple Cruz de caídos, si bien el conjunto estaba coronado por una cruz.

La Sentencia resulta absolutamente elocuente, al analizar el art. 15 de la LMH, en los siguientes términos: "en este momento lo que hay es un monolito de piedra, con una cruz, un escudo del Ayuntamiento de Buñuel, y una relación de nombres y apellidos, ni más ni menos [...] El hecho de que conste una relación de nombres y apellidos correspondientes a personas fallecidas, en un monolito en la puerta de una iglesia, no implica, por sí solo, exaltación alguna del franquismo a los efectos señalados en la Ley 52/2007. Precisamente, los símbolos franquistas que existían en dicho monolito fueron retirados, incluso alguno de ellos, al parecer, como consecuencia de la reclamación efectuada por la actora" -F.D. $3^{\circ}$-.

En este supuesto, al igual que en el anterior de Vigo, los "elementos franquistas" se habían hecho desaparecer antes del sometimiento de la cuestión a juicio. Por otro lado, y a diferencia de los casos enjuiciados en Cuenca, los Monumentos por los caídos no habían sido retirados por el Ayuntamiento respectivo, siendo que éste, en sostenimiento de su postura negativa a dicha retirada, había rechazado la procedencia de la aplicación de la LMH al caso.

\section{4. La Cruz de los Caídos de Callosa de Segura (Alicante)}

Rompiendo con esta línea jurisprudencial que, como hemos visto, se ha desenvuelto tanto respecto a la petición de remoción de Cruces de caídos contra la inacción municipal (casos navarro y gallego) como, contrariamente, respecto a la actuación del Consistorio en remoción de la Cruz (supuesto conquense), el Juzgado Cont.-Admvo. $\mathrm{N}^{\mathrm{o}} 1$ de Elche (Alicante) ha dictado - hasta el momento, ya que hay otros litigios, todavía sub iudice- dos Sentencias declarando ajustado a Derecho el acuerdo adoptado, en decisión mayoritaria, por el Pleno del Ayuntamiento de Callosa de Segura, acordando la retirada/destrucción de la Cruz de los caídos situada en la Plaza de España, si bien, dicen, los lugareños siempre se le ha llamado Plaza de la Iglesia, de dicha ciudad alicantina. Y de hecho, la Parroquia ha iniciado acciones judiciales en defensa de su titularidad dominical sobre la Plaza; litigio sumamente trascendente, pues de fallar los Tribunales a su favor, la actuación municipal no podrá tenerse si no por nula de pleno derecho, dado que quedaría demostrada su incompetencia en la materia. Pese a ello el Ayuntamiento ha procedido ya al desmantelamiento de la Cruz. 
En el primero de los supuestos resueltos judicialmente, en Sent. $N^{0}$ 541, de 30/10/2017, Iustel.com, RI $\S 419888$, de lo que se trataba, rectamente, era de la impugnación del rechazo del Ayuntamiento, mediante resolución de 26/1/2017, a la moción presentada por el Grupo Municipal del Partido Popular en relación a la memoria histórica, "Cruz de los Caídos", según resulta del F.D. $1^{\circ}$ de la Sentencia. Se asevera en la misma, para desestimar la demanda, que la parte actora no ha practicado prueba alguna, en el seno del procedimiento, en defensa de su postura, relativa a que en la actualidad, tras las obras de remodelación llevadas a cabo en la Cruz de los caídos callosina, la misma no infringe precepto alguno de la LMH. Por tanto, se afirma en la Sentencia, ha de rechazarse la pretensión litigiosa, conforme a las reglas relativas a la carga de la prueba (art. 217 LECivil), toda vez que la parte demandante no ha logrado acreditar "las obras de remodelación de la Cruz controvertida [...] que pudiera acreditar la conformidad del monumento en cuestión a la Ley 52/2007" -F.D. $2^{\circ}-$.

En el segundo supuesto, resuelto por la Sent. No 561, de 6/11/2017, Iustel.com, RI $\S 419889$, se rechaza expresamente la demanda interpuesta, en esta ocasión sí explícitamente contra el acuerdo municipal adoptado, el 3/3/2016, en remoción de la tan citada Cruz de caídos, que, en concreto, determinó: "eliminar/trasladar el Monumento a los Caídos y suprimir las placas conmemorativas presentes en el mismo, al tratarse de un objeto de exaltación colectiva de la guerra civil prohibido por la legislación vigente", según consta al F.D. $1^{\circ}$ de la Sentencia.

La argumentación de que se vale la Sentencia, para desestimar la demanda, es la de que la Cruz de los caídos no constituye un símbolo religioso; y, para llegar a tal conclusión, se vale de dos argumentos: 1) porque no se halla en un lugar de culto sino en una plaza pública del municipio y 2) "porque se erigió para conmemorar una sublevación militar y honrar a los vecinos de la localidad de Callosa pertenecientes a la facción ganadora que murieron durante la Guerra Civil Española, con la inscripción: ¡Presentes!, ocupando un lugar destacado el nombre de José Antonio Primo de Rivera".

De manera que, a tenor de esta resolución judicial, frente a lo que razonablemente podría esperarse de la lectura de la primera Sentencia (que parece se hubiera estado dispuesto a plantearse las consecuencias jurídicas que habrían de derivarse de que la Cruz hubiera sido despojada de los elementos apologético-franquistas), se asevera que el símbolo es irremediablemente franquista y ni siquiera despojándole de los añadidos más propiamente relativos a la Guerra o la Dictadura -lo que ya había tenido lugar antes del planteamiento del pleito- [así, por lo menos, se hace constar en el Voto particular que se contiene en la Sent. de 25/1/2018, Roj: STSJ CV 2/2018, recaída en recurso de apelación contra Auto adoptado en pieza de medidas cautelares; por lo que, estima la magistrada, se estaba en el caso del art 15.2 de la $\mathrm{LMH}$ ], la Cruz puede aspirar a no ser más que un símbolo evocador de religiosidad, y debe de hacérsele desaparecer del espacio público.

Trataremos en las líneas que siguen de desentrañar el sentido de estos "monumentos", haciéndolo a través de su recorrido en el tiempo.

\section{3. ¿LA CRUZ DE CAÍDOS ES EVOCADORA DE RELIGIOSIDAD O DEL FASCISMO?}

\subsection{Significado originario}

La doctrina suele atribuir un doble propósito al establecimiento de monumentos y cruces a los caídos: por un lado, un claro sentido apologético de la sublevación militar, la guerra civil 
$\mathrm{y}$, en definitiva, del régimen franquista; pero también, y no menos importante, se pretendía una finalidad de "apaciguar los ánimos de los familiares de las víctimas del bando vencedor [...] mediante el reconocimiento gráfico, público, explícito, de los caídos nacionales. Una manera de tratar de consolar a sus familiares y allegados por la pérdida sufrida era retratarlos como "héroes" y "mártires" en las páginas de la historia; y hacerlo a la vista de todos, en las múltiples placas que en cada iglesia evocaban a los muertos locales de un solo bando, en las cruces y monumentos que sembraron el paisaje español" (Aguilar, 2008: 145).

En efecto, así parece corroborarlo cuanto se dispone en la Orden del Ministerio de la Gobernación de 7/8/1939: "Con objeto de dar unidad de estilo y de sentido a la perpetuación por monumento de los hechos y personas de la Historia de España, y en especial a los conmemorativos de la guerra y en honor a los caídos, y para evitar que el entusiasmo, justificado en muchas ocasiones, pueda regir caprichosamente esta clase de iniciativas, sembrando desilusiones cuando se trata de proyectos no viables, este Ministerio se ha servido disponer lo siguiente: Art. $1^{\circ}$.- Todas las iniciativas de monumentos en general, incluso la apertura de suscripciones para su construcción, concursos de proyectos, etc., quedan supeditados a la aprobación de este Ministerio al cual deberán elevarse jerárquicamente, con informe de las autoridades que intervengan en el trámite. [...] Art. $3^{\circ}$.- Este Ministerio, por medio de la Jefatura del Servicio Nacional de Propaganda comunicará la resolución que recaiga sobre la oportunidad de las proposiciones y resolverá, en su caso, la forma en que haya de gestionarse el proyecto" [Orden del Ministerio de la Gobernación, de 7/8/1939, disponiendo queden supeditados a la aprobación de este Ministerio toda iniciativa de monumentos en general (BOE de 22/8/1939, p. 4614). Las cursivas son nuestras].

No obstante cuanto antecede, conviene no olvidar que en esa doble finalidad señalada siempre se involucra la creencia religiosa, en concreto la católica, y de ahí que se establezca una ligazón indisoluble con la "cruzada" y el tratamiento de "mártir" al caído en "defensa de la misma". Pero, sobre todo, es muy importante tener presente que, más que a decisión propia del Régimen dictatorial, tales actuaciones gubernamentales parecen responder a una pretensión de poner orden en iniciativas que se fueron adoptando motu proprio por el pueblo, tal y como se desprende de la Orden Ministerial transcrita, así como también de lo dispuesto, un año y medio antes, en la Orden de 20/2/1938, por la que se instituye la 'Comisión de Estilo en las Conmemoraciones de la Patria', la cual se justifica del siguiente modo: "La experiencia de otros países visitados por la guerra, y la que ya entre nosotros nos ha empezado a aleccionar, muestra los peligros, a veces irreparables, siempre de largos y difíciles cura y alivio, que para el decoro estético y hasta para la dignidad civil de las grandes urbes como de las modestas aldeas, significa el dejar abandonado a la iniciativa particular o a la espontánea y frecuentemente poco avisada de las Corporaciones locales, cuanto se refiere al estilo y realización de monumentos patrióticos, memoriales a los caídos, inscripciones lapidarias y otras formas materiales de homenaje, destinadas a multiplicarse, sin duda, y a través de las cuales aparece muchas veces retrospectivamente trocada la epopeya en caricatura" (BOE de 22/2/1938, p. 5897 s. La cursiva es nuestra).

$\mathrm{Y}$, es que, como se ha podido constatar, desde el mismo verano de 1936, "por doquier empiezan a surgir cruces y cruceros en homenaje y recuerdo de los héroes, de los mártires, de los caídos en la cruzada. Sobre las piedras seculares de las ermitas románicas, sobre los muros, sobre las fachadas de las altivas catedrales góticas, a las puertas de las iglesias, bajo los soportales y los aleros de las construcciones renacentistas, en las grandes poblaciones, en las pequeñas capitales de provincia y en los remotos pueblos, se inscriben en torno a los brazos de la cruz los nombres de los muertos en el bando de los vencedores" (Sueiro, 1976: 15. Cfr. Aguilar, 2008: 145). Ésta última, y no la relativa al establecimiento de cruces y 
monumentos, es la que sí parece que hay razones para sostener que tuvo un empuje más oficial, si bien en fecha tampoco tan temprana, pues es un Decreto de 16/11/1938, el que, "disponiendo las distintas formas de rendir homenaje a la memoria del héroe nacional y símbolo del sacrificio de la juventud española, J.A. Primo de Rivera", señala que "previo acuerdo con las autoridades eclesiásticas, en los muros de cada Parroquia figurará una inscripción que contenga los nombres de sus Caídos, ya en la presente Cruzada, ya víctimas de la revolución marxista"; dejando para un futuro el que "para conmemoración definitiva de J.A. Primo de Rivera, en su día se erigirá un monumento de importancia adecuada a los honores que en el presente Decreto se le señalan" [Decreto de la Jefatura del Estado de 16/11/1938 (BOE N ${ }^{\circ} 140$, de 17/11/1938, p. 2432), arts. $2^{\circ}$ y $7^{\circ}$. Las cursivas son nuestras].

En conclusión, el sentido apologético de las actuaciones normativo-gubernamentales del Régimen, en esta materia, no se apartan un ápice del sentido religioso con el que se ligaban indefectiblemente y que terminaron en su punto álgido en lo que se ha venido conociendo como el Nacionalcatolicismo, como es de sobra sabido (para una contextualización general en la materia: Cámara,1984); pero en este tipo de episodios no se puede descartar que, paralelamente a otros como el de la instauración en las aulas del Crucifijo y la presencia escolar de la Virgen, se tratase de un refrendo gubernamental que más que motu proprio lo fue interesadamente en beneficio del Régimen, de lo que "había sido un proceso generalizado, patrocinado por corporaciones católicas, Diputaciones y Universidades" (Álvarez, 1995: 392), anterior y, por tanto, al margen de la preceptiva jurídica.

De modo que la percepción del significado de todos esos símbolos, incluyendo todo lo relativo a los "Caídos", dependía mucho de la perspectiva que hubiera de adoptarse al respecto (Pineda, 2016: 79, después de analizar las disposiciones en la materia), pero no deja de ser representativo de una voluntad popular en la plasmación de una religiosidad, siquiera pudiera ser de tipo tradicional, en el ámbito público, si bien por iniciativa de los particulares. Y ello hasta el punto de que la postura oficial pudiera tenerse por algo despectiva respecto de estos impulsos populares, al haberse llegado a señalar que "la dimensión de nuestra Cruzada, los heroicos sacrificios que la victoria encierra y la trascendencia que ha tenido para el futuro de España esta epopeya, no pueden quedar perpetuados por los sencillos monumentos con los que suelen conmemorarse en villas y ciudades los hechos salientes de nuestra Historia y los episodios gloriosos de sus hijos", disponiéndose lo necesario para la puesta en escena de la faraónica obra del Valle de los caídos [así se señala en el Decreto de 1/4/1940, disponiendo se alcen Basílica, Monasterio y Cuartel de Juventudes, en la finca situada en las vertientes de la Sierra del Guadarrama (El Escorial), conocida por Cuelga-muros, para perpetuar la memoria de los caídos en nuestra Gloriosa Cruzada (BOE 2/4/1940, p. 2240). La cursiva es nuestra].

\subsection{Significado en el tardofranquismo, la Transición y primeros tiempos democráticos}

Aparte de la impronta legal, al menos por la presunción de legalidad propia del acto administrativo, si es que se considera que lo fue, por acción o inacción gubernativa..., que durante el Régimen pudiera atribuirse a los "Monumentos a los caídos"; éstos, especialmente si de Cruces se trataba o al menos la contenían, trascendidos de la confesionalidad propia de la época franquista, no parece descabellado llegar a aseverar que, en su tutela más exorbitante, pudieran llegar a considerarse como cosas sagradas (vid., sin embargo, la STS, Sala Penal, de 25/2/1993, F.D. $4^{\text {o }}$, en cuanto a la diferencia entre crucifijo y simple cruz, a estos efectos), con la protección que al respecto les otorgaba hasta el Código Penal, en adelante C.P., cuyo art. 208 sancionaba el delito de profanación (en efecto, el C.P. de 1973, ahora derogado, establecía, en su art. 208: "El que ejecutare actos de profanación en ofensa 
de los sentimientos religiosos legalmente tutelados, será castigado con la pena de prisión menor y multa de 100.000 a 500.000 pesetas.// Se impondrá esta pena en su grado máximo si los hechos previstos en el párrafo anterior fuesen realizados en templo, lugar destinado a culto o en ceremonia del mismo, oficialmente autorizadas, siempre que este requisito fuese necesario. //Cuando el hecho revistiese suma gravedad o relevante trascendencia, se aplicará la pena superior en grado". Esta situación se mantendría hasta bien entrada la Democracia, pues no es sino más de veinte años después de la muerte del dictador que, con el denominado C.P. de la Democracia, de 1995, un posible objeto sagrado deja de ser tal, a efectos penales y por lo que al delito en cuestión se refiere, si el mismo no está en templo o lugar de culto o bien que, situado fuera de él, se halle en el curso de un acto o ceremonia de tipo religioso (en efecto, como es conocido, el actual art. 524 del C.P. establece: "El que en templo, lugar destinado al culto o en ceremonias religiosas ejecutare actos de profanación en ofensa de los sentimientos religiosos legalmente tutelados será castigado con la pena de prisión de seis meses a un año o multa de 12 a 24 meses”). ¿Pero esta degradación en la tutela punitiva debe conllevar la pérdida del carácter religioso de un símbolo de este tipo? No parece, desde luego, si hubiera de atenderse el criterio de cuantos han impetrado el auxilio judicial en pro de la remoción de símbolos tales como la Cruz oriolana de la Sierra de la Muela, o el Cristo murciano de la pedanía de Monteagudo, o la efigie del Pilar de un cuartel de la Benemérita en Almodóvar del Río (Córdoba); pues, en todos estos casos, se ha atribuido, por parte de los demandantes, significado religioso al símbolo para subrayar la vulneración de la aconfesionalidad estatal y de la libertad de creencias del recurrente (un análisis en mayor profundidad de estos supuestos, en Alenda y Pineda, 2016, passim).

\subsection{Significado actual}

La superación de la etapa anterior -que, para algunos, no ha sido más que de "imperfecta Democracia"-, se ha pretendido mediante la adopción, entre otras medidas, de la tan ya mencionada LMH (cfr. García Amado, 2008: 62), virtud a la cual, y, en concreto, su art. 15, según propugnan algunos, $\mathrm{y}$, como hemos visto, ya ha sido recogido por alguna resolución judicial -que, incluso, ha devenido firme por la imposibilidad de recurso aneja a la cuantía, en el caso callosino-, la Cruz de caídos no es más que un vestigio franquista que es preciso retirar de los espacios públicos.

Hemos visto que esta solución se aparta de los precedentes en que, con voluntad política, se ha considerado superado el sentido apologético-franquista que se atribuye al "monumento", haciendo desaparecer del mismo los elementos franquistas propiamente dichos (caso, v.gr. de Alicante); voluntad política que, en ocasiones, actuada desde los Consistorios, sea por iniciativa propia o auspiciada por ediles o particulares, también ha sido confirmada por Tribunales de Justicia (como en los supuestos, ya vistos, resueltos por los TTSJ de Navarra y Galicia). En estos dos últimos casos, no obstante, siempre se podrá argumentar, de contrario, que el referido monumento ya había sido despojado de sus vestigios franquistas cuando se plantea el litigio; con lo cual, le hace perder fuerza al razonamiento judicial cuando tales "aditamentos" no se han "borrado" de la Cruz de caídos al impetrarse el auxilio de los Tribunales de Justicia. Pero, en supuestos como éste, incluso donde ha faltado consenso o voluntad política, como es el caso de los asuntos litigiosos de Mota del Cuervo (Cuenca), la autoridad judicial ha dispuesto la permanencia de la Cruz una vez despojada de los aditamentos franquistas.

Sin embargo, en el asunto callosino, y otros últimamente acaecidos, lo que se sostiene por el sector doctrinal y judicial dichos- es que, aun despojado de los aditamentos más propiamente apologéticos, el símbolo ha de ser retirado del espacio público por su carácter 
originario franquista y, por tanto, antidemocrático. Todo lo cual parece responder, tal y como se aseverado en la intelección del art. 15 de la LMH, a que "se persigue así, eliminar del espacio público todo elemento que perpetúe en la conciencia social una valoración favorable de todo aquello que se considera incompatible con los valores constitucionales que sustentan la convivencia social" (Camisón, 2013: 157).

Todo lo cual nos sumerge en la consideración relativa a que, en esta materia, las "dos Españas" vuelven a manifestarse y, desgraciadamente, con criterios que parecen propios de la confrontación "guerracivilista", puesto que lo que subyace en el fondo del asunto, aunque pueda ser una simplificación excesiva, es de si se trata, en efecto, de un vestigio franquista $o$, por el contrario, es un símbolo únicamente de carácter religioso.

\section{4. ¿LA CRUZ DE CAÍdOS ENTRA EN EL ÁMBITO DE APLICACIÓN DEL ART. 15.1 DE LA LMH?}

A tenor de cuanto hemos señalado, resulta, como mínimo, dudoso, que el significado histórico del símbolo sea propiamente franquista y, en cualquier caso, no habría dejado de ser, en origen y cumulativamente, de naturaleza religiosa, en el sentido de invocar una religión cual es la cristiana católica. ¿Qué sentido habría de prevalecer? La "apropiación franquista" de símbolos que son propiamente religiosos no puede hacer perder este sentido a las Cruces, por muy de "caídos" que sean. Las Cruces, por su origen -que es popular, por mucho que el Régimen franquista quisiera "sacar pecho" con las mismas- y por su propia sustantividad no pueden dejar de ser un símbolo religioso, pues los elementos apologéticos no constituyen más que un añadido en todo este conjunto. Sostener lo contrario no puede suponer sino sustantivar lo que no es más que meramente adjetivo; esto es, ver en una Cruz de caídos al "Caudillo" y no una evocación de "religiosidad". ¿Qué ve en ella un extranjero ajeno a la "historia" de esa Cruz?

Por otro lado, cabe preguntarse si, aunque, en origen, la Cruz fuera "franquista", que ya hemos visto que más bien no lo era, pero dialécticamente suscitamos la cuestión, ¿ese significado no puede haber variado en el tiempo? ¿El legislador "democrático-imperfecto" no le mudó su sentido convirtiéndolo incluso en objeto merecedor de la tutela penal durante más de 20 años después de la muerte de Franco y del abandono constitucional de la confesionalidad estatal?

En los tiempos actuales, ¿qué percibe un tercero, ajeno a la historia y a la conflictividad partidaria existente en la materia, ante una Cruz de caídos? ¿Si lo hace desde lejos, en que no se ve inscripción alguna? ¿Si lo mira desde cerca, desconociendo el significado de los nombres que puedan estar inscritos? Parece que el TSJ navarro lo habría expresado muy bien, tal y como lo hizo en la Sentencia, F.D. $3^{\circ}$, antes aludida: "en este momento, lo que hay es un monolito de piedra, con una cruz, un escudo del Ayuntamiento de Buñuel, y una relación de nombres y apellidos, ni más ni menos. Es evidente que una persona residente en Buñuel, y que ha conocido desde hace años el monolito, por mucho que se supriman leyendas, inscripciones u otros accesorios, conoce perfectamente cuál es el origen, pero no es menos cierto que, al contrario, cualquier persona ajena a la localidad, que contemplase el monolito en su estado actual, no lo podría relacionar fácil ni lógicamente con un pasado franquista".

Pues bien, como tiene dicho el Tribunal Constitucional, "debemos tomar en consideración no tanto el origen del signo o símbolo como su percepción en el tiempo presente, pues en una sociedad en la que se ha producido un evidente proceso de secularización es indudable que 
muchos símbolos religiosos han pasado a ser, según el contexto concreto del caso, predominantemente culturales aunque esto no excluya que para los creyentes siga operando su significado religioso" (STC 34/2011, de 28 de marzo, F.J.4. Las cursivas son nuestras); doctrina que, mutatis mutandi, nos parece perfectamente aplicable al caso, pues después de casi 80 años de paz y trascendido el símbolo de un significado de evocación de lo religioso, que nunca el franquismo pretendió que dejara de tener aunque lo fuera cumulativamente con la apología del Régimen, superado éste y mutado su sentido incluso por la actividad del legislador, no puede constituir una perversión, al punto de lo irrazonable, que un sector poblacional pretenda mantener, en cuanto que enraizado en su propio ser, una proyección de un sentimiento que, ya por cultura y tradición, no puede dejar de formar parte de la situación ambiental en que ha vivido durante tantos años, hasta el punto de llegar a sentirla como constitutiva de su propia identidad.

En cualquier caso, procede preguntarse si lo que se pretende con el art. 15 de la Ley 52/07 es la retirada del monumento o cruz, como tal, o lo que ordena es remover los elementos propiamente franquistas. Volvemos a insistir en que, primigeniamente, se trataba simplemente de añadir una "lista de caídos" a un soporte material, inmobiliario (cruces y paredes de iglesias, fundamentalmente), sin el cual no podía tener existencia alguna esa adición de nombres. Luego fueron surgiendo, a tales efectos, "Cruces de caídos" propiamente dichas, pero, ¿hay una parte sustantiva y otra adjetiva en la "Cruz-de-los-caídos"? Parece que la lectura que hacen algunos ha de interpretarse en el sentido de que el "monumento" constituye un todo indivisible o que lo predomina en él es la parte propiamente franquista, porque ni aun "liberándola" de los "elementos apologéticos del Régimen dictatorial" la Cruz puede permanecer en el espacio público. ¿Es, pues, necesario, retirar la completa Cruz, como tal, o basta con "remover/quitar" los aditamentos ensalzadores del franquismo de la misma?

A nuestro juicio, basta con quitar los "elementos franquistas" sin tener que retirar el "monumento" o "Cruz" en que se sitúan. Sostener lo contrario significa sustantivar lo que no pueden ser, materialmente y también por finalidad, más que "añadidos". Se trata de "Cruces", sustantivo, de "Caídos", adjetivo. Y no de "Caídos" en "Cruz". ¿O sí son "Caídos crucificados"? Ya hemos visto que, en origen, la disposición oficial franquista, al menos por lo que respecta al ya mencionado Decreto de 16/11/1938, no tenía otro sentido ni era con otra finalidad que el de añadir "listas de caídos" en elementos cristianos -muros de cada parroquia, se establecía- ya existentes (en nuestro criterio, ha de reputarse contrario el parecer de De Andrés, 2006: 16).

Por otro lado, que no baste con suprimir los elementos apologéticos porque la Cruz en sí es un vestigio franquista, resulta tanto como afirmar que una Cruz, como tal y sin más aditamentos, que hubiese sido dispuesta en el espacio público por obra del ya fenecido Régimen es merecedora también de su retirada de tal lugar. Pero no es esta postura, más bien representativa de una manifestación de laicismo radical anticatólico, la que ha sostenido nuestro TS con basamento, además, en la doctrina del TC y el TEDH. Y ello ante pretensiones de retirada de símbolos como el de la Cruz de la sierra de la Muela oriolana (calificada en la demanda, según la Sentencia, de "puro emblema del catolicismo impuesto por la dictadura franquista") o el Cristo murciano de la pedanía de Monteagudo ("reliquia del totalitarismo católico impuesto por el régimen de Franco", según los demandantes y a tenor de la Sentencia).

Al respecto, ha señalado el Tribunal Supremo, en Sentencias de 4/3/2013, Roj: STS 1798/2013, y de 2/12/2014, Roj: STS 5166/2014, en doctrina que constituye jurisprudencia, que "no basta con la mera referencia a que en un determinado lugar existan tales símbolos religiosos para entender que su permisividad por parte de las instituciones públicas 
compromete la aconfesionalidad del Estado cuando, como en este caso, están tan arraigados en la comunidad social que son consensuadamente aceptados y enmarcados dentro de la propia tradición cultural y asumidos como tales por el pueblo".

No parece, además, que el sentido de la LMH sea no hacer distinción entre lo que es principal y lo que es meramente accesorio en la Cruz, y ello si se toma en consideración:

$1^{\circ}$.- El art. 15 de la Ley que establece la retirada de los "elementos franquistas", dispone la misma bajo la rúbrica de "Símbolos y monumentos públicos" y es, por tanto, que, a los mismos se les han de retirar los "escudos, insignias, placas y otros objetos o menciones conmemorativas..."; esto es, no se establece la retirada de los símbolos y monumentos propiamente dichos, porque entonces la misma Ley los incluiría y lo diría clara y expresamente, con una dicción que podría ser del siguiente tipo: Los símbolos y monumentos públicos en que figuren escudos, placas, etc., conmemorativos... habrán de ser retirados.

$2^{\circ}$.- En este sentido, el propio art. 15, en su apartado 2, contempla una serie de excepciones a la retirada; excepciones que permiten discernir entre lo sustantivo y lo meramente adjetivo. Y, sobre todo, prueba de ello y viene a corroborar el argumento anterior es cuanto se dispone en la propia Ley respecto de la Cruz del Valle de los Caídos, pues, en ningún momento, se establece retirada, derribo o desaparición de la Cruz. Lo que se viene a ordenar es que se le desafecte de su apología franquista y se convierta en recuerdo de todas insistimos: todas, y, por tanto, de cualquier signo que sean- las víctimas (vid. art. 16 de la LMH. Acerca del régimen jurídico del Valle de los caídos: González-Varas, 2012).

$3^{\circ}$.- En la Proposición de Ley presentada por el PSOE para la reforma de la LMH -B.O. Cortes Generales. Congreso de los Diputados. Serie B: Proposiciones de Ley, No 190-1, 22/12/2017-, se incorpora un precepto en el que, con carácter explícito, se refiere a las Cruces de caídos, si bien que situadas en iglesias. Para este supuesto, lejos de procurar que se retiren tales Cruces, lo que se establece es que "la Iglesia Católica será requerida para la retirada de simbología de exaltación de la Guerra Civil Española en templos y cementerios, cruces de los caídos, o cualquier otro lugar de propiedad eclesiástica" (art. 28.2, cursiva nuestra). En consecuencia, no se pretende que se retiren las "Cruces de caídos", sino la simbología apologética del franquismo que puedan llevar "adicionada". En esta situación, lo que vale para una Cruz de caídos eclesiástica, ¿no sirve o puede valer para otra civil? Es cierto que una Proposición de Ley puede que llegue, finalmente, a quedar absolutamente en nada por lo que al mundo legislativo se refiere, pero al menos debería de servir como indicativo de cuál es la postura de un Grupo Parlamentario, al que sustenta todo el Partido Político que está detrás, al respecto. En este caso el PSOE, en el momento presente. ¿Un Grupo Municipal Socialista, de los muchos existentes a lo largo de la geografía hispana, no debería de quedar vinculado por este tipo de intelección de la LMH a todo este respecto?

\section{CONCLUSIONES}

Finalmente, ¿cuál es el sentido y finalidad de la Ley 52/2007 sobre el particular estudiado? A nuestro modesto entender:

La LMH no pretende perpetuar una situación "guerracivilista" sino, en todo caso, superarla y más bien por la vía de la conciliación y no la del enfrentamiento. Sin embargo, en el planteamiento y resolución de este conflicto, todo parece indicar que las "dos Españas" (y hasta de las "3 Españas" se ha llegado a hablar: Méndez, 2018) se manifiestan de nuevo, de no poder alcanzarse una solución que contente a las partes enfrentadas, que bien podría ser del tipo establecido en las tan referidas sentencias navarra y gallega, bien refrendando la 
previa actuación política, bien imponiendo este tipo de actuación, caso de las sentencias conquenses. ¿No resulta más adecuado mantener la Cruz sin sus elementos apologéticos en pro de la propia "Memoria histórica", tal y como se ha señalado en la ya referida STSJ gallego?

No se reputa que la Ley 52/2007 pretendiera propiciar una interpretación de la misma que parece resultar en agravio respecto de personas fallecidas. Sin embargo, las decisiones judiciales ilicitanas referidas, al acogerse al criterio de la Cruz como insuperablemente franquista, ¿no estarán abogando por una interpretación de la Ley que convierte a las Cruces de caídos y, en consecuencia -y quizás ello sea lo más importante-, a quienes en ellas figuren, con nombres y apellidos, en víctimas, sobrevenidas pero al fin postreras, del franquismo; tal y como si hubieran sido tales caídos los culpables de la apología de la sublevación y/o la guerra civil? En este sentido, ¿qué sucede con los caídos que, en concreto, con nombres y apellidos consten o figuren en las tan nombradas cruces? ¿En qué situación quedan? ¿Tienen que ser retirados, apartados, del lugar público en que se sitúan, irremediablemente? ¿Acaso no fueron víctimas de la Guerra Civil? ¿No se pretende la reparación, especialmente de tipo moral, de las víctimas? ¿De todas las víctimas? ¿O las de las Cruces de caídos se merecen ser "señaladas" con esa retirada? ¿Y eso sí que contribuye a la conciliación, reconciliación?

En las actuales circunstancias sólo resta esperar -y resulta altamente deseable- que alguno de estos supuestos pueda alcanzar el techo jurisdiccional del TS y, en su caso, del TC, con el objeto de determinar, de una vez por todas, cuál es la interpretación más ajustada a Derecho.

\section{BIBLIOGRAFÍA}

Abad Liceras, J.M. (2009) Ley de Memoria Histórica (La problemática jurídica de la retirada o mantenimiento de símbolos y monumentos públicos). Madrid: Dykinson.

Aguilar Fernández, P. (2008) Políticas de la Memoria y Memorias de la Política. Madrid: Alianza Editorial.

Alenda Salinas, M. y Pineda Marcos, M. (2016) El símbolo religioso en el Estado laico español. Valencia: Tirant Lo Blanch.

Álvarez Bolado, A. (1995) Para ganar la Guerra, para ganar la Paz. Madrid: Universidad Pontificia Comillas.

Cámara Villar, G. (1984) Nacional-catolicismo y escuela. La socialización política del franquismo (1936-1951). Jaén: Hesperia.

Camisón Yagüe, J.A. (2013) "Ley de Memoria Histórica: luces y sombras a propósito de las medidas de reparación”. En M. Criado de Diego (Dir.) El itinerario de la memoria. Derecho, historia y justicia en la recuperación de la memoria histórica en España, Vol. I: El derecho y la memoria. Madrid: Sequitur, pp. 127-159.

Campello, A. (2009) "La Cruz de [todos] los Caídos", en: www.alicantevivo.org/2009/01/la-cruz-detodos-los-caidos.html [consulta 6/6/2018].

CP (2017) "La Cruz de los Caídos de origen franquista seguirá en Calvo Sotelo", Información, en: www.diarioinformacion.com/alicante/2017/07/11/cruz-caidos-origen-franquista-seguira/1915752. html [consulta 6/6/2018].

De Andrés Sanz, J. (2006) "Los símbolos y la memoria del Franquismo". Fundación Alternativas, 23, en: www.fundacionalternativas.org/public/storage/estudios_documentos_archivos/xmlimportMf9 BZ4.pdf.

De Lemus Diego, M.T. (2014) "Los símbolos religiosos en la LMH”. Revista General de Derecho Canónico y Derecho Eclesiástico del Estado, 35: 1-29.

De Lemus Diego, M.T. (2016) Libertad religiosa, simbología y derecho comparado. Salamanca: 
Ediciones Universidad de Salamanca.

Europa Press (2018) "Una plataforma denunciará a la alcaldesa de Castellón si retira la cruz del parque Ribalta”. El Mundo, de 18/4/2018, en: www.elmundo.es/comunidadvalenciana/castellon/2018/ 04/18/5ad78851e2704e70398b45fc.html [consulta 1/6/2018].

Fernández de Gatta Sánchez, D. (2015) "Auto del TS (Sala de lo Militar) 5483/2015, de 29/6/2015 [ROJ: ATS 5483/2015], Auto del TS (Sala de lo Penal) 4884/2015, de 11/6/2015 [ROJ: ATS 4884/2015] y STSJ de Galicia (Sede de La Coruña) 536/2015, de 5/2/2015[ROJ: STSJ GAL 536/2015]. Tres ejemplos de una forma jurídicamente más adecuada de entender la "Memoria Histórica', pero... políticamente menos correcta”. Ars Iuris Salmanticensis, 3: 299-302.

García Amado, J.A. (2008) "Usos de la historia y legitimidad constitucional”. En J.A. Martín Pallín y R. Escudero Alday (Eds.) Derecho y memoria histórica. Madrid: Trotta, pp. 47-72.

González-Varas Ibáñez, A. (2012) "El Valle de los Caídos y su régimen jurídico: propuestas para una situación estable". Revista General de Derecho Canónico y Derecho Eclesiástico del Estado, 28: 136

Méndez, R. (2018) "Las tres Españas de Villarrobledo: "O tiran la estatua franquista o no habrá presupuestos"'. El Confidencial, 7/5/2018, en: https://www.elconfidencial.com/ espana/2018-0507/villarrobledo-presupuestos-ayuntamiento-monumento-franco-alzamiento_1559756/ [consulta $1 / 6 / 2018]$.

Muñoz-Rojas Oscarsson, O. (2018) Documento de reflexión sobre el futuro del Monumento a los Caídos de Navarra, en: www.pamplona.es/verdocumento/verdocumento.aspx?iddoc $=1361988$.

Pineda Marcos, M. (2016) "El poder legislativo ante la manifestación simbólico-religiosa". En M. Alenda Salinas y M. Pineda Marcos El símbolo religioso en el Estado laico español. Valencia: Tirant Lo Blanch, pp. 35-111.

Sueiro, D. (1976) La verdadera historia del Valle de los Caídos. Madrid: Sedmay.

\section{Breve currículo:}

\section{Manuel Alenda Salinas}

Catedrático de Derecho Eclesiástico del Estado en la Universidad de Alicante. Licenciado en Derecho por la Universidad de Alicante, Doctor en Derecho por la Universidad de Alicante. Tiene cuatro sexenios de investigación. Autor de La libertad de creencias y su tutela jurídica, Valencia, 2015 y "Repercusión de la doctrina, científica y jurisprudencial, en la nueva regulación reglamentaria del Registro de Entidades Religiosas. Anuario de Derecho Eclesiástico del Estado, 32, 2016: 1209-1248.

\section{Matilde Pineda Marcos}

Profesora Asociada de Derecho Eclesiástico del Estado en la Universidad de Alicante. Licenciada en Derecho por la UNED, Licenciada en Criminología por la Universidad de Alicante, Doctora en Derecho por la Universidad de Alicante, Abogada. Autora de "La simbología religiosa ante las Administraciones públicas”. En Alenda, M. y Pineda, M. El símbolo religioso en el Estado laico español. Valencia, 2016: 113-219 y de "Nuevos ámbitos de la presencia de signos reveladores de creencia religiosa en España". Revista General de Derecho Canónico y Derecho Eclesiástico del Estado, 48: 1-40. 